\title{
Efficacy of Different Doses of Dexmedetomidine in Blood Pressure to Laryngoscopy in Controlled Hypertensive Patient: A Randomized Control Trial
}

\author{
${ }^{*}$ Afroz $\mathrm{R}^{1}$, Begum $\mathrm{R}^{2}$, Alam $S^{3}$, Islam $\mathrm{MN}^{4}$, Muntakim $\mathrm{M}^{5}$, Zunaid $\mathrm{M}^{6}$, Jabed $\mathrm{M}^{7}$
}

\begin{abstract}
Control of blood pressure during anesthesia is very crucial. Laryngoscopic manipulation and endotracheal intubation are always a matter of concern which capable of producing tachycardia, arrhythmias and hypertension which is generally well tolerated in healthy patient. In hypertensive patient cardiovascular response to laryngoscopy and intubation is exaggerated. This study was conducted to assess the efficacy of different doses of dexmedetomidine in reduction of blood pressure during laryngoscopy and intubation in controlled hypertensive patient. This prospective Randomized controlled trial was carried out among 60 patients belonging to American Society of Anesthesiologists (ASA) Physical Status II posted for elective general anesthesia. Patients were randomly divided into three groups where each groups contain twenty with fixed card sampling. Group A consisted of twenty (20) patients who were received $I V$ dexmedetomidine $0.5 \mu \mathrm{g} / \mathrm{kg}$ diluted to $50 \mathrm{ml}$ with normal saline. Group $B$ consisted of twenty (20) patients who were received IV dexmedetomidine $0.75 \mu \mathrm{g} / \mathrm{kg}$ diluted to $50 \mathrm{ml}$ with normal saline. Group $C$ consisted of twenty (20) patients who were received $I V$ dexmedetomidine $1 \mu \mathrm{g} / \mathrm{kg}$ diluted to $50 \mathrm{ml}$ with normal
\end{abstract}

1. *Dr. Rumana Afroz, Registrar, Department of Neuroanaesthesia and Neurocritical Care, Apollo Hospitals Dhaka. preith007@yahoo.com

2. Dr. Rabeya Begum, Professor and Head of the Department of Anaesthesia, Greenlife Medical College, Dhaka.

3. Dr. Shafiqul Alam, Associate Professor, Department of Anaesthesia, Analgesia, Intesive and Palliative Care, Dhaka Medical College, Dhaka.

4. Dr. Md Nurul Islam, Associate Professor, Department of Anaesthesia, Analgesia, Intesive and Palliative Care, Dhaka Medical College, Dhaka.

5. Dr. Mahin Muntakim, Medical Officer, DGHS. tanzilmahin85@gmail.com

6. Dr. Md Zunaid, Medical Officer, Dhaka Medical College.

7. Dr. Md Jabed, Assistant Professor (CC), DPM, DGHS.

* For correspondence saline. Each infusions were started 10 minutes prior induction of general anesthesia and were given over 10 minutes. Baseline systolic blood pressure (SBP), diastolic blood pressure (DBP) and mean arterial blood pressure (MAP) were measured by one volunteer anesthesiologists by non-invasive blood pressure monitor. Following laryngoscopy and endotracheal intubation, the parameters recorded were SBP, DBP and $M A P$ at 1, 3 and 5 min after intubation by non-invasive blood pressure monitor. The primary outcome measures were blood pressure responses after intubation and secondary outcome measures were to note down any adverse effects associated with drugs.

In this study baseline readings of SBP, DBP and MAP were almost similar in all three groups and statistically not significant. Maximum intubation response was seen at $1 \mathrm{~min}$ post intubation in all the three groups. The mean SBP of group $A$ varied from $144.8 \pm 8.4 \mathrm{mmHg}$ to $118.5 \pm 4.4 \mathrm{mmHg}$ that of group $B$ varied from $134.8 \pm 4.1$ to $122.0 \pm 4.2 \mathrm{mmHg}$ and then group $C$ varied from $126.5 \pm 15.5 \mathrm{mmHg}$ to $103.8 \pm 8.4$ $m m H g$ during different evaluation period $(p<0.05)$. The mean DBP of group $A$ varied from $91.8 \pm 7.6 \mathrm{mmHg}$ to $72.4 \pm 5.8 \mathrm{mmHg}$ that of group $B$ varied from $81.3 \pm 5.2$ to $70.3 \pm 2.5 \mathrm{mmHg}$ and then group C varied from $80.9 \pm 6.7$ $\mathrm{mmHg}$ to $63.4 \pm 2.4 \mathrm{mmHg}$ during different evaluation period $(p<0.05)$. The mean MAP of group $A$ varied from $109.0 \pm 5.6 \mathrm{mmHg}$ to $87.5 \pm 4.4 \mathrm{mmHg}$ that of group $B$ varied from $98.7 \pm 2.5$ to $86.3 \pm 3.4 \mathrm{mmHg}$ and then group $C$ varied from $95.5 \pm 9.2 \mathrm{mmHg}$ to $76.5 \pm 3.4 \mathrm{mmHg}$ during different evaluation period $(p<0.05)$. The mean SBP at 1 st hour was found 127.9 \pm 6.5 in group $A, 131.6 \pm 6.4$ group $B$ and $131.5 \pm 7.1$ group $C$. The DBP at 1st hour was found $126.8 \pm 6.4$ in Group $A, 131.4 \pm 6.8$ in Group $B$ and $131.8 \pm 6.1$ in Group C. The mean MAP at 1st hours was found 93.2 \pm 3.7 in group $A, 95.4 \pm 3.4$ in Group $B$ and 96.2 \pm 4.9 in Group $C(p>0.05)$. Dexmedetomidine in doses of $0.75 \mu \mathrm{g} / \mathrm{kg}$ was more effective compared to $0.05 \mu \mathrm{g} / \mathrm{kg}$ and $1 \mu \mathrm{g} / \mathrm{kg}$ in attenuating blood pressure response to laryngoscopy and endotracheal intubation without producing adverse effects in control hypertensive patients.

Keywords: Efficacy; different doses; dexmedetomidine; blood pressure; laryngoscopy; controlled hypertensive patient; randomized control trial 


\section{INTRODUCTION}

Dexmedetomidine is effective during intubation at the time of anaesthesia. ${ }^{1}$ In addition, it maintained intraoperative cardiovascular stability. These drugs decrease tachycardia, hypertension, and sympathetic activity, which are beneficial for the cases with a presence of myocardial ischemia. ${ }^{2}$

Various researchers of different countries have suggested that dexmedetomidine is significantly reduced the haemodynamic responses during laryngoscopy and endotracheal intubation among the hypertensive patients. ${ }^{3}$ Choudhury et $\mathrm{al}^{4}$ and Sulaiman et $\mathrm{al}^{3}$ have both performed two separate studies by using dexmedetomidine with a dose of $0.05 \mu \mathrm{g} / \mathrm{kg}$ for reduction of blood pressure responses during laryngoscopy and endotracheal intubation. The pretreatment with dexmedetomidine 0.05 $\mu \mathrm{g} / \mathrm{kg}$ attenuate the stress responses, but did not totally abolish the cardiovascular and catecholamine surge responses to tracheal intubation. Smitha et $\mathrm{al}^{5}$ have used dexmedetomidine with the dose of 0.5 and $1 \mu \mathrm{g} / \mathrm{kg}$ and have found that the dose of $1 \mu \mathrm{g} / \mathrm{kg}$ is more effective for the reduction of stress response to laryngoscopy and endotracheal intubation. However, this is a promising results; furthermore the dose of $1 \mu \mathrm{g} / \mathrm{kg}$ is associated with some incidence of cardiovascular system. Sebastian et $\mathrm{al}^{6}$ have used dexmedetomidine $(0.75 \mu \mathrm{g} / \mathrm{kg})$ for reduction of stress response to laryngoscopy and endotracheal intubation. In $0.75 \mu \mathrm{g} / \mathrm{kg}$ group, intubation responses is completely obtunded when compared to $0.5 \mu \mathrm{g} / \mathrm{kg}$ without any adverse effects.

Appropriate premedication can prevent the associated risks of heamodynamic pressure response to laryngoscopy and intubation in controlled hypertension patients; which is essential to prevent negative outcomes such as tachycardia, hypertension, myocardial ischemia, ventricular arrhythmias. Dexmedetomidine is highly specific and selective potent alpha-2 agonist which produces dose dependent sedation anxiolytics and analgesia. It can potentially offer a superior effect in attenuating stress-induced sympathoadrenal responses during laryngoscopy. In addition, many perioperative beneficial characteristics stated earlier, made it an attractive drug to study. It reduces the requirement of both intravenous and inhalational anaesthetics ${ }^{7}$, thus reducing their side effects, achieve hemodynamic stability during the intra-operative period and maintains intraoperative cardiovascular stability.
Therefore, the search of effective dose of dexmedetomidine premedication for controlled hypertensive patients uncovering the possibilities for better management of those patient with less side effects in perioperative period and reduce mortality and morbidity. So the aim of the present study was to assess the effectiveness of dexedetomidine in attenuation of blood pressure due to laryngoscopy and endotracheal intubation with different doses of intravenous dexmedetomidine in controlled hypertensive patients.

\section{MATERIALS AND METHODS}

Study Population and Settings: This single blind, parallel randomized controlled trial was conducted in Department of Anaesthesia, Analgesia, Palliative and intensive Care Medicine, Dhaka Medical College Hospital, Dhaka from August 2016 to July 2018 for a period of two (02) years. Data was gathered after approval of protocol by ethical review committee. Patients who were categorized as American society of Anesthesiology (ASA) class II, patients who had a history of essential hypertension for which they were being treated and controlled as well as posted for elective surgeries under general anesthesia were selected as study population. Any anticipated difficult intubation or patients who had a history of bronchial asthma, drug or alcohol abuse, patients who had a history of cerebrovascular, neurologic, respiratory or ischemic heart disease and renal or hepatic dysfunction, patients who were physically dependent on narcotics, known drug allergy to dexmedetomidine, patients on antidepressants, anxiolytics, anticonvulsant or antipsychotics, pregnant or nursing woman, participation in another drug study during the preceding 1 month period were excluded from this study.

Randomization and Blinding: A total number of sixty (60) patients belonging to ASA Physical Status II posted for elective general anaesthesia was finally selected. All the information were recorded in a prefixed data sheet. Patients were randomly divided into three groups and each group had twenty patients. Randomization allocated by fixed card sampling. One assigned anesthesiologist performed the grouping. Data were collected by the volunteer anaesthesiologist who was expert enough take data and was fully unaware of the study.

\section{INTERVENTION}

Group A consisted of twenty (20) patients who were received IV dexmedetomidine $0.5 \mu \mathrm{g} / \mathrm{kg}$ diluted to $50 \mathrm{ml}$ with normal saline as infusion over $10 \mathrm{~min}$. Group B consisted of twenty (20) patients who were received IV 
dexmedetomidine $0.75 \mu \mathrm{g} / \mathrm{kg}$ diluted to $50 \mathrm{ml}$ with normal saline as infusion over $10 \mathrm{~min}$. Group $\mathrm{C}$ consisted of twenty (20) patients who were received IV dexmedetomidine $1 \mu \mathrm{g} / \mathrm{kg}$ diluted to $50 \mathrm{ml}$ with normal saline as infusion over $10 \mathrm{~min}$. All infusions were started 10 minutes prior induction of general anesthesia. All patients were evaluated a day before surgery. The patients were kept fasting overnight after 10:00 pm and was received tablet Ranitidine $150 \mathrm{mg}$ orally and tablet midazolam $7.5 \mathrm{mg}$ orally as premedication at night before surgery. The same anaesthesiologist prepared the intravenous (IV) infusions of dexmedetomidine. All patients monitored with non-invasive blood pressure monitor (philips sure signs VS3). An IV line was secured, and the patients were administered $500 \mathrm{ml}$ of IV fluid Ringer's lactate. Baseline systolic blood pressure (SBP), diastolic blood pressure (DBP), mean arterial blood pressure (MAP) were measured by one volunteer anaesthesiologists by non-invasive blood pressure monitor. Then study drug infusion was given over 10 min by principal investigator. All the patients were pre-oxygenated for 3 minutes. Then, patients was induced with IV Thiopental Sodium $5 \mathrm{mg} / \mathrm{kg}$ body weight, IV fentanyl $1 \mu \mathrm{g} / \mathrm{kg}$, endotracheal intubation was facilitated by IV succinylcholine $1.5 \mathrm{mg} / \mathrm{kg}$ body weight. Laryngoscopy and intubation was done by principal investigator.

Follow up and Outcome Measures: Following laryngoscopy and endotracheal intubation, the parameters recorded was SBP, DBP and MAP at 1, 3 and 5 min after intubation by non-invasive blood pressure monitor. After adequate recovery, patients were shifted to post-anaesthesia care unit and monitored for 2 hours. The principle investigator was assessing the patients directly postoperatively in the recovery room and was also personally follow-up the patients in the ward for monitoring purposes. If any unforeseen complication occurs in the ward, the principle investigator was available to come and examine the patient, address and manage any problems.

Statistical analysis: All the parameters were expressed as mean and standard deviation (mean $\pm \mathrm{SD}$ ) and percentage. ANOVA for repeated measures followed by post hoc analysis with Least Significance Difference (LSD) was performed for comparing continuous variables within the groups at different time points. For intragroup comparison at the same time point, between the groups, Students ' $t$ ' test was applied. $p$ value $<0.05$ was accepted as level of significance. Statistical analyses were performed by using a computer based statistical program SPSS (Statistical Package for Social Sciences) Version 22 with the help of a biostatistician.

\section{RESULT}

Table I shows this present study was carried out with an aim to find out the specific dose of Dexmedetomidine in attenuation of blood pressure response to laryngoscopy and tracheal intubation in controlled hypertensive patients without adverse effects. The groups were well matched for their demographic data. Male to female ratio was 1:1 in all three group. The basal readings of blood pressure were similar in all the three groups. Maximum intubation response was seen at 1 min post-intubation in all the three groups. Regarding the side effects it was observed that Hypotension was found in 6(30.0\%) cases in group C and hypertension was found in $4(20.0 \%)$ cases of group $\mathrm{A}$. The difference was statistically significant $(\mathrm{p}<0.05)$ among three groups. The mean age were $45.2 \pm 3.1$ years in group A, $50.3 \pm 7.4$ years in group $B$ and $47.5 \pm 7.9$ years in group C. Male was found $10(50.0 \%)$ in group A, $10(50.0 \%)$ in group B and $10(50.0 \%)$ in group C. The difference was statistically not significant $(\mathrm{p}>0.05)$ among three groups (Table 1).

Table 1: Age and Gender Distribution of the Study Participant $(n=60)$

\begin{tabular}{|l|c|c|c|c|}
\hline Variables & Group A (n=20) & Group B (n=20) & Group C (n=20) & P value \\
\cline { 1 - 3 } Mean Age (Years) & $45.2 \pm 3.1$ & $50.3 \pm 7.4$ & $47.5 \pm 7.9$ & \multirow{2}{*}{ a $0.053^{\text {ns }}$} \\
\cline { 1 - 3 } Range(min-max) & 33 to 43 & 40 to 60 & 35 to 60 & \\
\cline { 1 - 3 } Gender & & & $10(50.0 \%)$ & \multirow{2}{*}{ b $1.000^{\text {ns }}$} \\
\cline { 1 - 3 } - Male & $10(50.0 \%)$ & $10(50.0 \%)$ & $10(50.0 \%)$ & \\
\hline - Female & $10(50.0 \%)$ & $10(50.0 \%)$ & \\
\hline
\end{tabular}

$\mathrm{ns}=$ not significant; ${ }^{\mathrm{a}} \mathrm{p}$ value reached from ANOVA test; ${ }^{\mathrm{b}} \mathrm{p}$ value reached from Chi- square test; Data are expressed as Mean $\pm \mathrm{SD}$ 
Table II shows the baseline mean Systolic blood pressure was found $130.2 \pm 6.5(\mathrm{mmHg})$ in group $\mathrm{A}, 135.6 \pm 4.3$ $(\mathrm{mmHg})$ in group $\mathrm{B}$ and $134.9 \pm 11.9(\mathrm{mmHg})$ in group $\mathrm{C}$. The Baseline difference was statistically not significant ( $p>0.05$ ) among three groups. The mean SBP of group A varied from $144.8 \pm 8.4 \mathrm{mmHg}$ to $118.5 \pm 4.4 \mathrm{mmHg}$ that of group B varied from $134.8 \pm 4.1$ to $122.0 \pm 4.2 \mathrm{mmHg}$ and then group $\mathrm{C}$ varied from $126.5 \pm 15.5 \mathrm{mmHg}$ to $103.8 \pm 8.4$ $\mathrm{mmHg}$ during different evaluation period. The difference was statistically significant $(\mathrm{p}<0.05)$ among three groups.

Table II: Distribution of the Study Participant by Systolic Blood Pressure ( $n=60)$

\begin{tabular}{|c|c|c|c|c|}
\hline Systolic blood pressure $(\mathrm{mmHg})$ & Group A $(n=20)$ & Group B $(n=20)$ & Group C $(n=20)$ & $P$ value \\
\hline Baseline & $130.2 \pm 6.5$ & $135.6 \pm 4.3$ & $134.9 \pm 11.9$ & \multirow[t]{2}{*}{$0.086 \mathrm{~ns}$} \\
\hline Range(min-max) & 120 to 140 & 130 to 142 & 127 to 158 & \\
\hline After drug administration & $118.5 \pm 4.4$ & $129.0 \pm 5.5$ & $124.5 \pm 10.9$ & \multirow[t]{2}{*}{$0.001 \mathrm{~s}$} \\
\hline Range(min-max) & 110 to 122 & 120 to 137 & 110 to 143 & \\
\hline $1 \mathrm{~min}$ & $144.8 \pm 8.4$ & $134.8 \pm 4.1$ & $126.5 \pm 15.5$ & \multirow[t]{2}{*}{$0.001 \mathrm{~s}$} \\
\hline Range(min-max) & 130 to 155 & 130 to 140 & 105 to 145 & \\
\hline $3 \min$ & $128.6 \pm 5.8$ & $126.3 \pm 5.7$ & $112.2 \pm 8.9$ & \multirow[t]{2}{*}{$0.001 \mathrm{~s}$} \\
\hline Range(min-max) & 118 to 135 & 120 to 135 & 100 to 124 & \\
\hline $5 \mathrm{~min}$ & $119.1 \pm 8.0$ & $122.0 \pm 4.2$ & $103.8 \pm 8.4$ & \multirow[t]{2}{*}{$0.001 \mathrm{~s}$} \\
\hline Range(min-max) & 105 to 128 & 118 to 130 & 90 to 120 & \\
\hline
\end{tabular}

$s=$ significant; $n s=$ not significant; $p$ value reached from ANOVA test; Data are expressed as Mean $\pm S D$

Table III shows the baseline mean diastolic blood pressure baseline (DBP) was found $79.8 \pm 2.2(\mathrm{mmHg})$ in group A, $80.6 \pm 3.7(\mathrm{mmHg})$ in group $\mathrm{B}$ and $82.2 \pm 4.5(\mathrm{mmHg}) \mathrm{C}$. The Baseline difference was statistically not significant ( $p>0.05$ ) among three groups. The mean DBP of group A varied from $91.8 \pm 7.6 \mathrm{mmHg}$ to $72.4 \pm 5.8 \mathrm{mmHg}$ that of group B varied from $81.3 \pm 5.2$ to $70.3 \pm 2.5 \mathrm{mmHg}$ and then group $\mathrm{C}$ varied from $80.9 \pm 6.7 \mathrm{mmHg}$ to $63.4 \pm 2.4$ $\mathrm{mmHg}$ during different evaluation period. The difference was statistically significant $(\mathrm{p}<0.05)$ among three groups.

Table III: Distribution of the study participant by diastolic blood pressure ( $n=60)$

\begin{tabular}{|c|c|c|c|c|}
\hline Diastolic BP (mmHg) & Group A $(n=20)$ & Group B (n=20) & Group C $(n=20)$ & $P$ value \\
\hline Baseline & $79.8 \pm 2.2$ & $80.6 \pm 3.7$ & $82.2 \pm 4.5$ & \multirow[t]{2}{*}{$0.108 \mathrm{~ns}$} \\
\hline Range(min-max) & $75-82$ & $75-87$ & $80-92$ & \\
\hline After drug administration & $72.4 \pm 5.8$ & $73.7 \pm 4.2$ & $78.1 \pm 5.7$ & \multirow[t]{2}{*}{$0.003 \mathrm{~s}$} \\
\hline Range(min-max) & $60-80$ & $70-82$ & $70-86$ & \\
\hline $1 \mathrm{~min}$ & $91.8 \pm 7.6$ & $81.3 \pm 5.2$ & $80.9 \pm 6.7$ & \multirow[t]{2}{*}{$0.001 \mathrm{~s}$} \\
\hline Range(min-max) & $79-100$ & $78-85$ & $71-90$ & \\
\hline $3 \mathrm{~min}$ & $86.3 \pm 6.5$ & $75.7 \pm 2.9$ & $73.1 \pm 6.7$ & \multirow[t]{2}{*}{$0.001 \mathrm{~s}$} \\
\hline Range(min-max) & $75-95$ & $70-80$ & $68-90$ & \\
\hline $5 \mathrm{~min}$ & $77.8 \pm 3.9$ & $70.3 \pm 2.5$ & $63.4 \pm 2.4$ & \multirow[t]{2}{*}{$0.001 \mathrm{~s}$} \\
\hline Range(min-max) & $70-82$ & $65-75$ & $60-68$ & \\
\hline
\end{tabular}

$s=$ significant; $p$ value reached from ANOVA test; Data are expressed as Mean \pm SD 
Table IV shows the baseline mean MAP was found $96.8 \pm 4.1(\mathrm{mmHg})$ in group $\mathrm{A}, 98.3 \pm 3.8(\mathrm{mmHg})$ in group B and 100.3 $\pm 7.1(\mathrm{mmHg})$ in Group C. The Baseline difference was statistically not significant $(p>0.05)$ among three groups. The mean MAP of group A varied from $109.0 \pm 5.6 \mathrm{mmHg}$ to $87.5 \pm 4.4 \mathrm{mmHg}$ that of group B varied from $98.7 \pm 2.5$ to $86.3 \pm 3.4 \mathrm{mmHg}$ and then group $\mathrm{C}$ varied from $95.5 \pm 9.2 \mathrm{mmHg}$ to $76.5 \pm 3.4 \mathrm{mmHg}$ during different evaluation period. The difference was statistically significant $(\mathrm{p}<0.05)$ among three groups.

Table IV : Distribution of the study participant by MAP $(n=60)$

\begin{tabular}{|c|c|c|c|c|}
\hline MAP (mmHg) & Group A $(n=20)$ & Group B $(n=20)$ & Group C (n=20) & $P$ value \\
\hline Baseline & $96.8 \pm 4.1$ & $98.3 \pm 3.8$ & $100.3 \pm 7.1$ & \multirow[t]{2}{*}{$0.113 \mathrm{~ns}$} \\
\hline Range(min-max) & 91 to 106 & 93 to 105 & 95 to 114 & \\
\hline After drug administration & $87.5 \pm 4.4$ & $91.9 \pm 3.7$ & $92.6 \pm 7.7$ & \multirow[t]{2}{*}{$0.007 \mathrm{~s}$} \\
\hline Range(min-max) & 80 to 94 & 88 to 99 & 83 to 104 & \\
\hline $1 \mathrm{~min}$ & $109.0 \pm 5.6$ & $98.7 \pm 2.5$ & $95.5 \pm 9.2$ & \multirow[t]{2}{*}{$0.001 \mathrm{~s}$} \\
\hline Range(min-max) & 101 to 117 & 96 to 103 & 84 to 108 & \\
\hline $3 \min$ & $99.9 \pm 4.3$ & $91.8 \pm 4.2$ & $85.9 \pm 5.4$ & \multirow[t]{2}{*}{$0.001 \mathrm{~s}$} \\
\hline Range(min-max) & 94 to 106 & 85 to 97 & 80 to 96 & \\
\hline $5 \min$ & $91.4 \pm 3.4$ & $86.3 \pm 3.4$ & $76.5 \pm 3.4$ & \multirow[t]{2}{*}{$0.001 \mathrm{~s}$} \\
\hline Range(min-max) & 84 to 96 & 80 to 93 & 70 to 82 & \\
\hline
\end{tabular}

$s=$ significant; $p$ value reached from ANOVA test; Data are expressed as Mean \pm SD.

Table $\mathrm{V}$ shows the mean SBP at $1^{\text {st }}$ hour was found $127.9 \pm 6.5$ in Group A, 131.6 \pm 6.4 Group B and 131.5 \pm 7.1 Group C. The DBP at $1^{\text {st }}$ hour was found $126.8 \pm 6.4$ in Group A, 131.4 \pm 6.8 in Group B and 131.8 \pm 6.1 in Group
C. The mean MAP at $1^{\text {st }}$ hours was found $93.2 \pm 3.7$ in group A, 95.4 \pm 3.4 in Group B and 96.2 \pm 4.9 in Group C. The difference hour was statistically not significant ( $>0.05)$ among three groups.

Table V : Distribution of the Study Participant by Blood Pressure in Post-Operative period ( $n=60)$

\begin{tabular}{|c|c|c|c|c|}
\hline BP in Post-Operative Period & Group A $(n=20)$ & Group B $(n=20)$ & Group C $(n=20)$ & P value \\
\hline \multicolumn{5}{|l|}{ SBP $(\mathrm{mmHg})$} \\
\hline - 1 st hour & $127.9 \pm 6.5$ & $131.6 \pm 6.4$ & $131.5 \pm 7.1$ & \multirow[t]{2}{*}{$0.145 \mathrm{~ns}$} \\
\hline - $\quad$ Range(min-max) & 115 to 138 & 120 to 140 & 115 to 140 & \\
\hline - 2nd hour & $127.2 \pm 6.4$ & $131.4 \pm 6.8$ & $131.8 \pm 6.1$ & \multirow[t]{2}{*}{$0.0510 \mathrm{~ns}$} \\
\hline - $\quad$ Range(min-max) & 120 to 137 & 123 to 142 & 120 to 142 & \\
\hline \multicolumn{5}{|l|}{$\mathrm{DBP}(\mathrm{mmHg})$} \\
\hline - 1 st hour & $76.3 \pm 3.4$ & $77.7 \pm 2.83$ & $79.0 \pm 4.3$ & \multirow[t]{2}{*}{$0.065 \mathrm{~ns}$} \\
\hline - $\quad$ Range(min-max) & 70 to 80 & 75 to 82 & 70 to 84 & \\
\hline - 2nd hour & $76.0 \pm 3.8$ & $76.8 \pm 3.7$ & $78.4 \pm 2.4$ & \multirow[t]{2}{*}{$0.081 \mathrm{~ns}$} \\
\hline - $\quad$ Range(min-max) & 72 to 82 & 72 to 82 & 72 to 80 & \\
\hline \multicolumn{5}{|l|}{ MAP $(\mathrm{mmHg})$} \\
\hline - 1 st hour & $93.2 \pm 3.7$ & $95.4 \pm 3.4$ & $96.2 \pm 4.9$ & \multirow[t]{2}{*}{$0.061 \mathrm{~ns}$} \\
\hline - $\quad$ Range(min-max) & 85 to 99 & 91 to 100 & 85 to 101 & \\
\hline - 2nd hour & $93.2 \pm 4.1$ & $95.3 \pm 4.3$ & $96.1 \pm 3.1$ & \multirow[t]{2}{*}{$0.058 \mathrm{~ns}$} \\
\hline - $\quad$ Range(min-max) & 88 to 99 & 89 to 100 & 89 to 100 & \\
\hline
\end{tabular}

$s=$ significant; $n s=$ not significant; $\mathrm{p}$ value reached from ANOVA test; Data are expressed as Mean $\pm \mathrm{SD}$. 


\section{DISCUSSION}

In this present study, the mean age was $45.2 \pm 3.1$ years in group A, 50.3 \pm 7.4 years in group B and $47.5 \pm 7.9$ years in group C. The difference was statistically not significant ( $p>0.05$ ) among three groups. Samala et $\mathrm{al}^{8}$, Pramanick et $\mathrm{al}^{9}$ and Smitha et $\mathrm{al}^{5}$ found almost similar mean age and age ranged in their respective studies. On the other hand Sebastian et $\mathrm{al}^{6}$ found the mean age was $32.50 \pm 9.12$ years

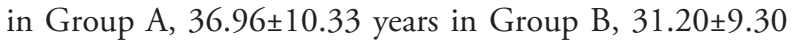
years in Group C, which is smaller with the present study. The lower mean age and age range maybe due to geographical variations, racial, ethnic differences, and genetic causes.

In this study, dexmedetomidine is effective significantly in blunting the increase in mean SBP and DBP due to laryngoscopy and intubation. However, the baseline difference of mean SBP and DBP is not statistically significant $(p>0.05)$ among the group A, B and C. Though mean SBP and DBP have been increased at 1 minute after intubation in all three groups. The haemodynamic variables fell below the base line in group $B$ and $C$ all the time. The findings indicates that there is a disparity of SBP and DBP in group $A$ and group $C$ but in group $B$ it was almost unswerving from baseline to 5 minutes follow-up. Inter group comparison revealed statically significant among three groups $(\mathrm{p}<0.05)$. Smitha et $\mathrm{al}^{5}$ compared the effect of 0.5 and $1 \mu \mathrm{g} / \mathrm{kg}$ of dexmedetomidine with normal saline in attenuating stress response. They found out that dexmedetomidine $1 \mu \mathrm{g} / \mathrm{kg}$ was more effective than dexmedetomidine $0.5 \mu \mathrm{g} / \mathrm{kg}$ in controlling haemodynamic responses to tracheal intubation. The intergroup comparison revealed a statistically significant $(\mathrm{p}<0.05)$. Similar observations regarding the SBP and DBP were also Samala et $\mathrm{al}^{8}$, Pramanick et $\mathrm{al}^{9}$ and Sebastian et $\mathrm{al}^{6}$.

At baseline, the MAP $(\mathrm{P}=0.113)$ is almost same among the group $\mathrm{A}, \mathrm{B}$ and $\mathrm{C}$. However, it has been also found that group $\mathrm{B}$ and group $\mathrm{C}$ have a significantly lower MAP $(\mathrm{p}=0.001)$ to $5 \mathrm{~min}$ follow up. Dexmedetomidine attenuates sypathatoadrenal response by activation of presynaptic $\alpha 2$ receptors in sympathetic nerve endings resulting in decreased release of noradrenaline. Moreover, stimulation of postsynaptic $\alpha 2$ receptors of locus coeruleus causes inhibition of norepinephrine release ${ }^{10}$. Patel et $\mathrm{al}^{11}$ have administered dexmedetomidine intravenously as loading dose of $1 \mu \mathrm{g} / \mathrm{kg}$ over $10 \mathrm{~min}$ prior to induction in group $\mathrm{B}$ and observed, dexmedetomidine significantly attenuated stress response to intubation with lesser increase in systolic (6\% vs. 23\%) and diastolic (7\% vs. 20\%) blood pressure as compared to the control group $(\mathrm{P}<0.05)$.
In this current study, the baseline mean MAP is $96.8 \pm 4.1$ $(\mathrm{mmHg})$ in group $\mathrm{A}$; however, in group $\mathrm{B}$ and group $\mathrm{C}$ the MAP are slightly higher that group A which are $98.3 \pm 3.8$ $(\mathrm{mmHg})$ and $100.3 \pm 7.1 \quad(\mathrm{mmHg})$ respectively. The baseline difference of mean arterial pressure among these three groups is not statistically significant $(p>0.05)$. Maximum intubation response is found at $1 \mathrm{~min}$ post-intubation among the three groups. In group B, they approached near the baseline by 3 minutes. Interestingly, the variables fell below the baseline by $3 \mathrm{~min}$ in group $\mathrm{C}$. In group A statistically higher values of SBP, MAP at all-time intervals are found in post-intubation when compared to group B and group C. Therefore, it can be inferred that the haemodynamic response is better observed in group B and group C, when it is compared with group A. However, the parameters fell below the baseline value at $1 \mathrm{~min}$ after intubation in group $\mathrm{C}$. This clearly indicates that the dexmedetomidine in a dose of $0.75 \mu \mathrm{g} / \mathrm{kg}$ and $1 \mu \mathrm{g} / \mathrm{kg}$ is superior to dexmedetomidine in a dose of $0.5 \mu \mathrm{g} / \mathrm{kg}$.

Similarly Sebastian et $\mathrm{al}^{6}$ showed the mean of Mean Arterial Blood Pressure (MAP) in first minute $114.57 \pm 5.14 \mathrm{mmHg}$ in Group A, 98.87 $\pm 5.86 \mathrm{mmHg}$ in Group B and $96.33 \pm 5.40 \mathrm{mmHg}$ in Group C $(p<0.001)$. In third minute $108.47 \pm 4.97 \mathrm{mmHg}$ in Group $\mathrm{A}$, $94.83 \pm 5.13 \mathrm{mmHg}$ in Group B and $90.27 \pm 5.49 \mathrm{mmHg}$ in Group C $(p<0.001)$. In fifth minute $103.37 \pm 4.51 \mathrm{mmHg}$ in Group A, $91.80 \pm 5.48 \mathrm{mmHg}$ in Group B and $85.47 \pm 5.08 \mathrm{mmHg}$ in Group $\mathrm{C}(p<0.001)$. Similar observations regarding the MAP pressure was also reported by Smitha et $\mathrm{al}^{5}$.

In this present study, hypotension is found in 6(30.0\%) in group C. In group A hypertension has found in 4(20.0\%) cases. The differences among the three groups is statistically significant $(\mathrm{p}<0.05)$. Smitha et $\mathrm{al}^{5}$ have reported that different doses of dexmedetomidine has shown irregular breathing with varied episodes of apnoea. Furthermore, dexmedetomidine $(1 \mu \mathrm{g} / \mathrm{kg})$ has been associated with the increased incidence of adverse effects like bradycardia and hypotension observed by Kartik et $\mathrm{al}^{12}$ and Menda et $\mathrm{al}^{13}$. It has been established that the activation of post-synaptic $\alpha-2$ receptors in CNS brings the decreased sympathetic activity which can lead to bradycardia as well as hypotension ${ }^{14}$. Furthermore dexmedetomidine $(1 \mu \mathrm{g} / \mathrm{kg})$ is associated with increased incidence of adverse effects ${ }^{13}$.

Yallapragada et $\mathrm{al}^{15}$ have been reported that the dexmedetomidine $(1 \mu \mathrm{g} / \mathrm{Kg})$ is effective on the blood 
pressure responses during laryngoscopy and intubation showed that BP increased by $4.0 \%$ initially but later declined by $11.0 \%$ following a 5 minute infusion of dexmedetomidine. After intubation the SBP rose only slightly above baseline. In four patients in dexmedetomidine Group hypotension (SBP $<90 \mathrm{mmHg}$ ) was observed following induction of anaesthesia. In this study also six patients had developed hypotension in group C.

Patients have been shifted to the post anaesthesia care unit after complete clinical recovery and they have been observed for 2 hours for nausea, vomiting, bradycardia, hypotension and sedation. In present study results suggested that to control blood pressure during laryngoscopy and tracheal intubation, Dexmedetomidine is a better drug and $0.75 \mu \mathrm{g} / \mathrm{kg}$ dose is more effective than Dexmedetomidine with the dose of $0.5 \mu \mathrm{g} / \mathrm{kg}$ and $1 \mu \mathrm{g} / \mathrm{kg}$ which causes no significant side effects in controlled hypertensive patients. In this study no significant respiratory depression, apnea, muscle rigidity or decrease in $\mathrm{SpO}_{2}$ was seen in any patient in post-operative period.

\section{CONCLUSIONS}

It can be concluded that Dexmedetomidine dose of 0.75 $\mu \mathrm{g} / \mathrm{kg}$ is safe and effective in obtunding the blood pressure response to laryngoscopy and endotracheal intubation without producing side effects compared to doses of 0.5 $\mu \mathrm{g} / \mathrm{kg}$ and $1 \mu \mathrm{g} / \mathrm{kg}$.

\section{REFERENCES}

1. Agarwal, S., Gupta, K., Singh, V.P., Sharma, D. and Pandey, M.N., 2016. Comparative evaluation of dexmedetomidine with clonidine as premedication for attenuation of hemodynamic responses during laryngoscopy and endotracheal intubation under general anesthesia. International Journal of Research in Medical Sciences, 4(9), pp.4026-32.

2. Krishna K.N.G., 2011. Effect of Dexmedetomidine on perioperative haemodynamics, anaesthtic requirements and recovery characteristics in patients undergoing transnasal trans sphenoidal resection of pituitary tumor. Thesis.

3. Sulaiman, S., Karthekeyan, R.B., Vakamudi, M., Sundar, A.S., Ravullapalli, H. and Gandham, R., 2012. The effects of dexmedetomidine on attenuation of stress response to endotracheal intubation in patients undergoing elective off-pump coronary artery bypass grafting. Annals of Cardiac Anaesthesia, 15(1), pp.39-43.

4. Choudhary, K.R., Kaushik, A., Sharma, S. And Puri, S.K.S., 2017. A Randomized Controlled Study on Effect of Dexmeditomidine for Stress Response Attenuation due to Laryngoscopy and Intubation. International Journal of Medical Research Prof, 3(3), pp. 219-22.

5. Smitha, K.S., Shukla, D., Sathesha, M., Rao, N.S. and Sudheesh, K., 2014. Comparison of two different doses of dexmedetomidine in attenuating hemodynamic changes during laryngoscopy. Journal of Evolution of Medical and Dental Science, 3, pp.13501-8.

6. Sebastian, B., Talikoti, A.T. and Krishnamurthy, D., 2017. Attenuation of haemodynamic responses to laryngoscopy and endotracheal intubation with intravenous dexmedetomidine: A comparison between two doses. Indian Journal of Anaesthesia, 61(1), pp.48-54.

7. Aantaa, R., Kanto, J., Scheinin, M., Kallio, A. and Scheinin, H., 1990. Dexmedetomidine, an alpha2-adrenoceptor agonist, reduces anesthetic requirements for patients undergoing minor gynecologic surgery. Anesthesiology, 73(2), pp.230-235.

8. Samala, S. and Indurkar, P.S., 2017. Effect of intravenous dexmedetomidine $(1 \mu \mathrm{g} / \mathrm{kg})$ in obtunding the pressor response to laryngoscopy and tracheal intubation compared to intravenous preservative free $2 \%$ lignocaine $(1.5 \mathrm{mg} / \mathrm{kg})$. International Journal of Research in Medical Sciences, 4(7), pp.2750-55.

9. Pramanick, S., Sadaqat S.H. and Banerjee, P.B.D., 2016 Attenuation of haemodynamic response to different doses of dexmedetomidine during extubation in patients undergoing peripheral vascular surgery. Indian Journal of Basic and Applied Medical Research, 5(4), pp.740-751.

10. Prasad, S.R., Matam, U.M. and Ojili, G.P., 2015. Comparison of intravenous lignocaine and intravenous dexmedetomidine for attenuation of hemodynamic stress response to laryngoscopy and endotracheal intubation. Journal of Dr. NTR University of Health Sciences, 4(2), pp.86-90.

11. Patel, N.D., Patel, J.J. and Patel, D.D., 2015. A study on comparison of intravenous dexmedetomidine with intravenous fentanyl for suppression of hemodynamic responses to laryngoscopy and endotracheal 
intubation during general anaesthesia. National Journal Medical research 5(2), pp.127-131.

12. Kartik, S., Bunty S., Gian C. And Avinash G., 2018. Dexmedetomidine Versus Esmolol for Attenuation of Haemodynamic Response to Laryngoscopy and Tracheal Intubation in Hypertensive Patients. International Journal of Anatomy, Radiology and Surgery 7(1), PP.1-5.

13. Menda, F., Koner, O., Sayin, M., Ture, H., Imer, P. and Aykac, B., 2010. Dexmedetomidine as an adjunct to anesthetic induction to attenuate hemodynamic response to endotracheal intubation in patients undergoing fast-track CABG. Annals of Cardiac Anaesthesia, 13(1), pp. 16-20.

14. Paranjpe, J.S., 2013. Dexmedetomidine: Expanding role in anesthesia. Medical Journal of Dr. DY Patil Vidyapeeth, 6(1), pp.5-13

15. Yallapragada, S.V., Vidadala, K.S., Vemuri, N.N. and Shaik, M.S., 2014. Comparison of the efficacy of dexmedetomidine with that of esmolol in attenuating laryngoscopic and intubation response after rapid sequence induction. Anesthesia, Essays and Researches, 8(3), pp.383-387. 